\title{
Morphometrics of Scinaia latifrons (Nemaliales, Rhodophyta) in the Southwestern Gulf of California, Mexico
}

\author{
Karla León-Cisneros and Rafael Riosmena-Rodriguez* \\ Programa de Investigacion en Botanica Marina, Departamento de Biologia Marina, \\ Universidad Autonoma de Bja California Sur, Apartado postal 19-B, La Paz B.C.S. 23080 Mexico
}

\begin{abstract}
Scinaia latifrons Howe occurs in rhodolith beds between 9 to $27 \mathrm{~m}$ depths at San Lorenzo channel, Gulf of California, Mexico. As very little was known about the morphometrics of this normally temperate species in a subtropical area, we investigated the phenological changes from December 1998 to December 1999. The gametophytic phase of the species was present from late February to late May, which represented a shorter time period to other known species in the genus. Our results suggested that two gametophytic cohorts develop over winter and early spring based on the size class structure of the frond height. Thalli became reproductively mature at a small size (1-2 cm in height) and all the plants were monoecious. Scinaia latifrons at the study location underwent allometric growth, indicated by the lack of correlation between size, width of the plants, or branching patterns.
\end{abstract}

Key Words: Morphometrics, Gulf of California, Scinaia latifrons, Mexico

\section{INTRODUCTION}

Most modern studies of Scinaia have been concerned with taxonomic and morphological aspects (Huisman 1986, 1987; Kajimura 1988) of the genus in temperate areas. In those studies it has been suggested that the gametophytic phase of several species of this genus, and other related genera, develops over a 6 month period (Table 1). Only basic developmental information derived from culture studies is was available (Ramus 1969; Aguilera and Ganesan 1981). It is not known how plants change over time and basic morphometrics information such as frond height, width and thallus densities is lacking. Also unknown is how often and at what plant size reproductive maturity is attained.

Scinaia latifrons was originally described by Howe (1911: 500) based on morphometric features. Dawson (1949: 237) added that the species is dioecious. The geographic distribution of the species included the coldtemperate Californian area (Channel Is.) to the subtropical area in the Gulf of California (Abbott and Hollenberg 1976). In the Gulf of California it was one of the dominant species associated with rhodolith beds at 9 -

*Corresponding author (riosmena@uabcs.mx)
$12 \mathrm{~m}$ depths (Steller et al. 2003). We hypothesized that the life span of the gametophytic phase would be temporally restricted in this subtropical area in relation to other species in the genus in temperate areas.

The aims of the present study were therefore to: (1) determine the major morphometrical changes (frond height, apical and middle width) in the gametophytic phase of Scinaia latifrons; (2) determine the density of plants over time; (3) determine the plant size in where reproductive maturity is attained.

\section{MATERIALS AND METHODS}

Sampling of Scinaia was undertaken at 12-13 $\mathrm{m}$ depths in San Lorenzo Channel $\left(110^{\circ} 20^{\prime} \mathrm{W}\right.$; between $24^{\circ} 25^{\prime}$ and $24^{\circ} 20^{\prime} \mathrm{N}$ ), from December 1988 to December 1999. During the first six months sampling was undertaken every two weeks and, after the gametophytic phase disappeared, every month were looking for the sporophyte and protonemal gametophyte phases. During each visit, two random sites were selected around the south channel buoy marker (see Fig. 1 from Foster et al., 1997 for a description of the locality). At each site a $50 \mathrm{~m}$ transects were used to determine the density of the population over time in one square meter quadrat placed each meter. At the same time at least 7-10 
Table 1. Comparative analysis of the seasonal presence of some Scinaia and Gloiophloea species in relation to temperature and geographic distribution

\begin{tabular}{|c|c|c|c|c|}
\hline \multirow{2}{*}{ Species } & \multirow{2}{*}{ Geographic distribution } & \multicolumn{2}{|c|}{ Gametophyte phase } & \multirow{2}{*}{ Source } \\
\hline & & Season & Temperature range $\left({ }^{\circ} \mathrm{C}\right)$ & \\
\hline Scinaia latifrons & $\begin{array}{l}\text { Japan, Korea, China, California to } \\
\text { Gulf of California }\end{array}$ & $\begin{array}{c}\text { February - May } \\
\text { (end winter - end spring) }\end{array}$ & $16-22$ & This study \\
\hline S. aborealis & $\begin{array}{l}\text { Western, Southern and Eastern } \\
\text { Australia (Not Tasmania) }\end{array}$ & $\begin{array}{l}\text { August - January } \\
\text { (winter - summer) }\end{array}$ & $14-19$ & Millar (1990) \\
\hline S. australis & $\begin{array}{l}\text { Southern Australia and } \\
\text { New South Wales }\end{array}$ & $\begin{array}{c}\text { July - January } \\
\text { (winter - summer) }\end{array}$ & $10-17$ & Millar (1990) \\
\hline S. moniliformis & Australia, Japan, India and Philippines & $\begin{array}{c}\text { July - January } \\
\text { (winter - summer) }\end{array}$ & $10-17$ & Millar (1990) \\
\hline Gloiophloea scinaioides & $\begin{array}{l}\text { Western Australia, Victoria and } \\
\text { Tasmania }\end{array}$ & $\begin{array}{l}\text { December - May } \\
\text { (summer - fall) }\end{array}$ & $10-17$ & Huisman (1987) \\
\hline
\end{tabular}

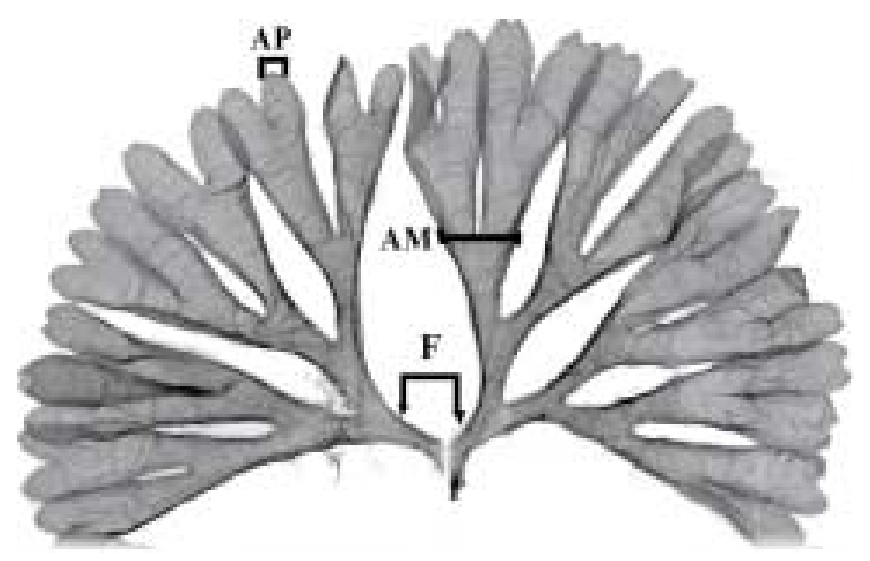

Fig. 1. Habit of Scinaia latifrons showing the presence of fronds (F), apical width (AP) and middle width (AM) measured in the present study.

clumps were collected, when possible, to determine the variation in size structure and determine reproduction of the population. All collected materials were transported immediately to the laboratory for morphometric and anatomical analyses.

In the laboratory the number of fronds per thallus and the number of dichotomies per frond were counted. Each plant was divided into fronds and each frond height, apical and median widths frond (Fig. 1) were measured with a rule ( $\pm 0.25 \mathrm{~mm}$ standard error). Finally, the ratio of mature to immature fronds was established. All mature plants were examined microscopically to evaluate the ratio of male to female individuals. Voucher materials were deposited in the Herbarium of UABCS [FBCS] with the catalog numbers 7243-7247.

For the estimation of frond size, we collected 90 individuals over 5 sampling dates (dates: 21 February
1999, 07 March 1999, 18 March 1999, 03 April 1999, 18 April 1999, 09 May 1999; during early March it was not possible to sample because of logistic and weather problems). We found an average of 1.8 fronds per thallus and we measured an average of 3.7 main branches per frond; thus we obtained 336 data points per measured structure (height, middle and apical width) over the 5 dates. Because of small plant numbers, to test independence a one way ANOVA was performed to establish if fronds can be used as a basic unit, the analysis showing marked differences between height frond $(\mathrm{p}<0.05)$. We calculated the mean and standard deviation of frond per date during the period of study. After this, we developed histograms of size-class of fronds and width-class per date. To construct the size class intervals from the histograms, we calculated the mean increment in length between two dates and the overall increment of all dates. The results were very consistent using both methods for all measured structures $(2.0 \mathrm{~cm}$ for height, $0.5 \mathrm{~cm}$ for apical width and $0.20 \mathrm{~cm}$ for median width).

Normality and homoscedasticity were evaluated for all the measurable information (height, apical and middle width) collected by Kolmogorov-Smirnov and by Cochran test (Zar 1996). Non-normality of some months was detected (even after transformation), but homoscedasticity was met, in this case robustness of the analysis was assumed (Zar 1996) and a one way (time) ANOVA Model I was performed. Once any significant differences were detected, we used an a posteriori Tukey test. In addition to this, a linear correlation between height, number of dichotomies per frond and median width was tested. To determine if there was any 


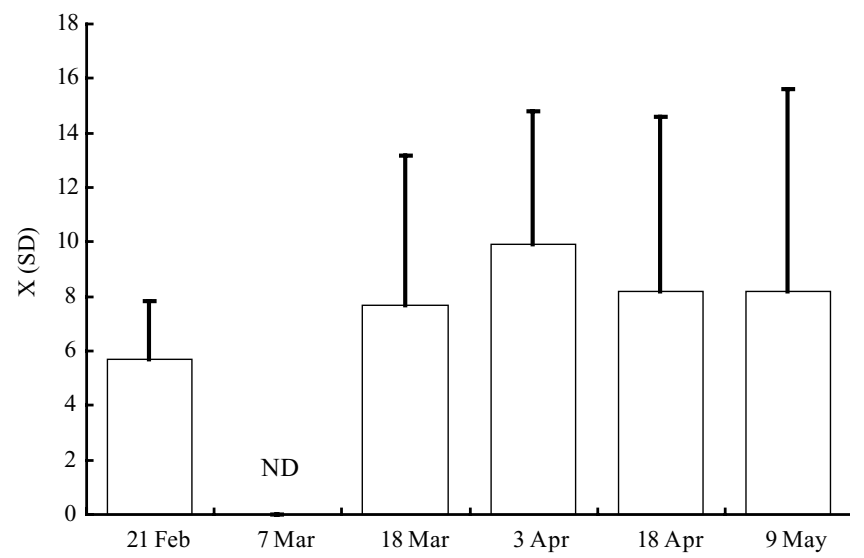

Fig. 2. Temporal variation of Scinaia latifrons thalli mean $( \pm \mathrm{SE})$ height at San Lorenzo Channel.

relationship between morphological parameters and environmental variables, we used the Spearman rank correlation (Zar 1996) between our measurements and available data on photoperiod (Robles-Gil 1998) and temperature (Flores-Ramirez 1994).

\section{RESULTS}

During this study the gametophytic phase of Scinaia latifrons was present from late February to late May. Tetrasporophytes were not detected at any time. Plant density was with an average of only 0.19 thallus $\cdot \mathrm{m}^{-2}$. However, the density did vary between months, with the highest density on April 18 at 0.3 thallus $\cdot \mathrm{m}^{-2}$ and the lowest in May 09 at to 0.06 thallus $\cdot \mathrm{m}^{-2}$. With respect to linear correlation, we found a good correlation between height and number of dichotomies $(r=0.87)$ but no correlation between frond height and apical or median width $(r<0.59)$. Moreover, we found no significant correlation $(r<0.30)$ between the measured parameters and environmental variables (photoperiod and temperature).

Average frond height increased gradually, with a maximum height measured on April 3 and minimum height measured on May 9 (Fig. 2). The mean and standard deviation were consistent between most of the sampling dates and the ANOVA $(n=5, p<0.001)$ showed significant statistical differences between dates. The a posteriori Tukey analysis showed that the main differences occurred between February 21 and April 3, but not in relation to other dates.

Fifteen size-classes were determined based on the frond height data, and temporal changes in the frequency of particular classes were observed (Fig. 3).
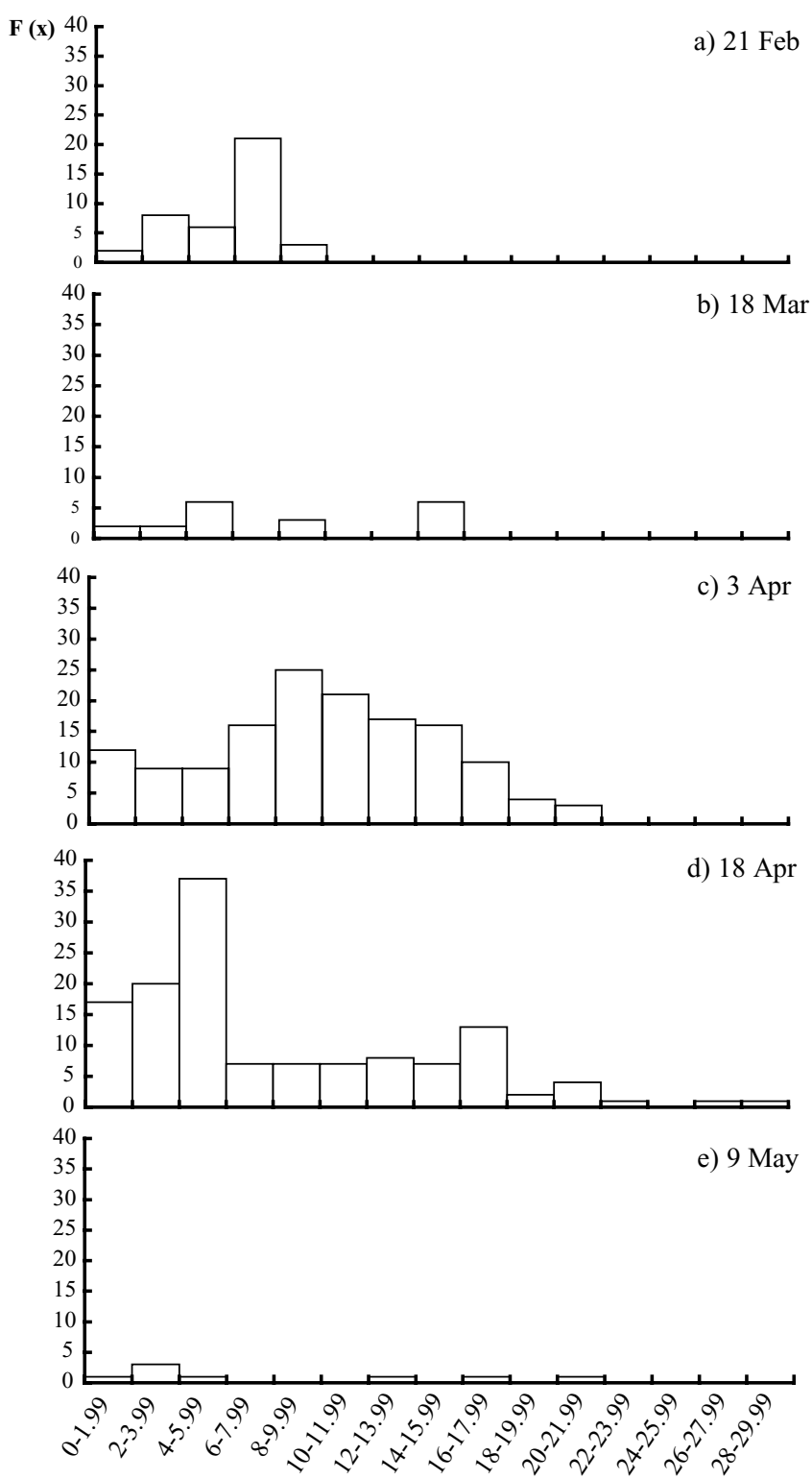

Fig. 3. Size class frequency histograms of frond height observed over time, dates are indicated by the letter $(a, b, c, d, e)$.

Five size-classes were present in February and March (Fig. 3a-b). All the plants in February were in the lower size class, with their mode in the $8-9.99 \mathrm{~cm}$ range, while in March there were two modes, one in the smaller class range $(4-5.99 \mathrm{~cm})$ and the other in the medium class range $(14-15.99 \mathrm{~cm})$ and most of other size class with similar values. On April 3, there was an increase in the number of size classes to eleven (Fig. 3c), but without a clear mode. They included five small-size classes (0-9.99 $\mathrm{cm})$ and five medium-size classes $(10-19.99 \mathrm{~cm})$, and one large-size class $(20-21.99 \mathrm{~cm})$. For April 18, (Fig. 3d) we found almost all the size-class with the exception of one $(24-25.99 \mathrm{~cm})$. Finally, in May 9 we found 6 classes with very low number of observations (Fig. 3e). 


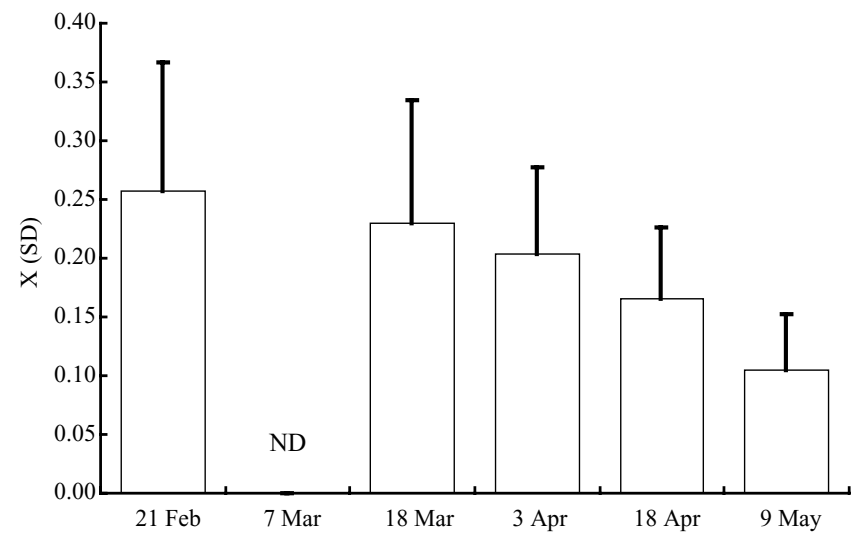

Fig. 4. Temporal variation of Scinaia latifrons frond apical width (AP from fig. 1) mean ( \pm SE) wide at San Lorenzo Channel.

Apical width decreased over time (Fig. 4). Maximum mean apical width was observed in February and the minimum in May (Fig. 4). This observation was statistically significant $(\mathrm{n}=5, \mathrm{p}<0.001)$ between sampling dates. The Tukey analysis showed that February/March are significantly different from April/May $(p<0.01)$ with no significant differences within those pairs of months.

Twelve width classes were determined based on the data, and temporal changes in their frequencies were observed (Fig. 5). In this case in February we found a widely distributed histogram (Fig. 5a), with all the size classes represented except the smallest and with a mode in the middle width-class $(0.25-0.29 \mathrm{~cm})$. On March 18 the histogram was narrower and there was not an identifiable mode (Fig. 5b). On April 3 there was a noticeable increment and the number of observations per width-class represented and the mode is present in the $4^{\text {th }}-6^{\text {th }}$ width-class (Fig. 5c). During April we found a decrease in the observed width-classes but the mode is maintained in the $5^{\text {th }}$ and $6^{\text {th }}$ width-classes (Fig. 5d). The above pattern was maintained during the first visit of May (Fig. 5e).

Regarding temporal variation in the median width, we found no major changes during the study period. There were no detectable statistical differences among the sampling dates (Fig. 6). The widest plants (mean $=0.69$ $\mathrm{cm}$ ) occurred in March, and the narrowest were found in February $($ mean $=0.53 \mathrm{~cm})$. The standard deviation was constant during the study.

Minimum height of reproductive plants was $1.5 \mathrm{~cm}$. Gametophytes; we observed that all plants were monoecious. Spermatangia occurred in dense sori scattered through out the thallus and carposprangia
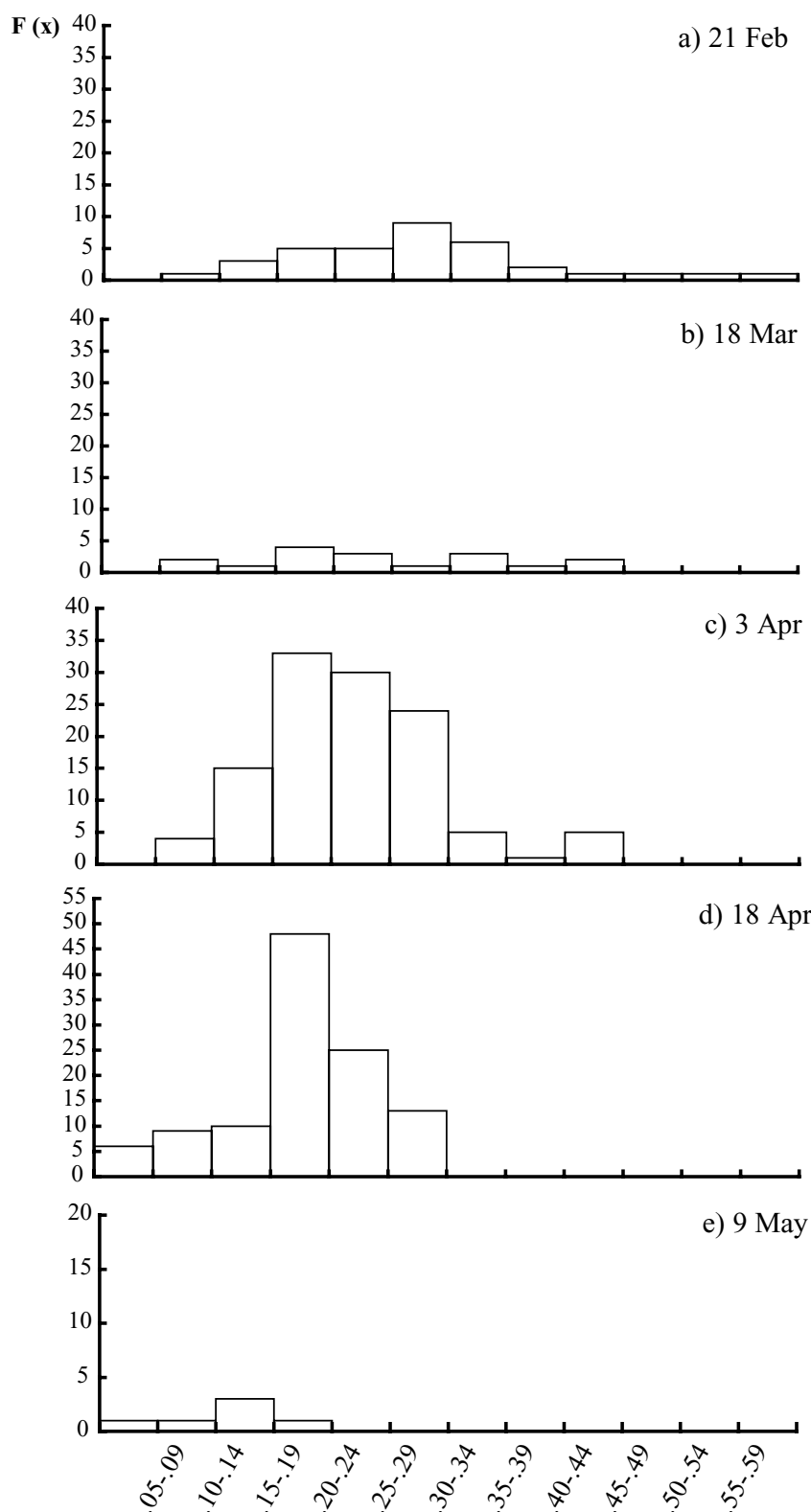

Fig. 5. Size class frequency histograms of frond apical width (AP from fig. 1) observed during the sampling dates, dates are indicated by the letter $(a, b, c, d, e)$.

were commonly observed. The spermatangial branches were located between the utricles and had 2 or 3 branches and were $5-10 \mu \mathrm{m}$ in length.

\section{DISCUSSION}

Our results indicate that the gametophytic phase of Scinaia latifrons is present from mid winter to mid spring at San Lorenzo Channel. Noticeable differences in the frequency of individuals of each size-class over the months (Fig. 3) suggest that two cohorts might develop. The first cohort appeared in February and began to 


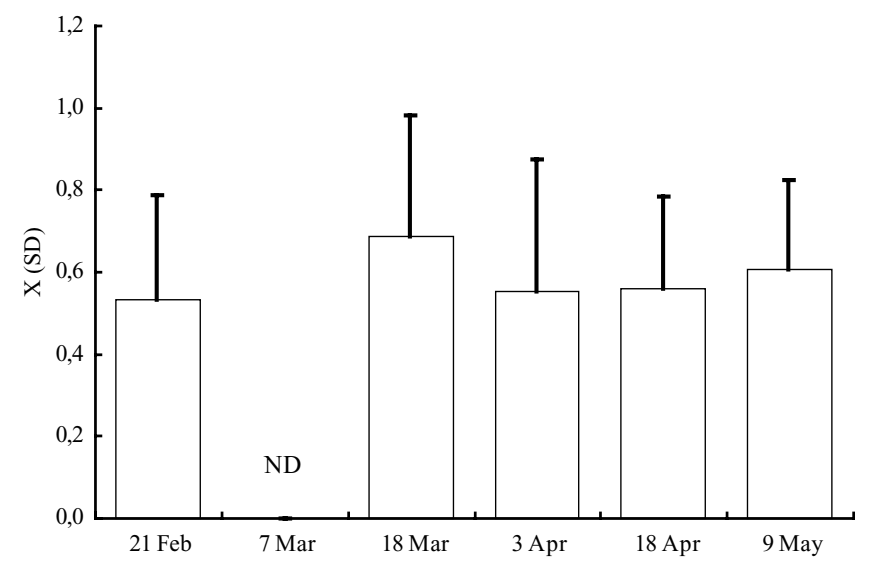

Fig. 6. Temporal variation of Scinaia latifrons frond middle width $(\mathrm{AM})$ mean $( \pm \mathrm{SE}) \longrightarrow$ wide at San Lorenzo Channel.

disappear late in April, when we found the largest plants but at low numbers (Fig. 3c). The second cohort began to develop late in April when there was an abundance of smaller plants and the potential recruitment of individuals was clear (Fig. 3d). Unfortunately, most of these plants were senescent (with many epiphytes) suggesting that this second cohort could not mature because of environmental stress. This is consistent with significant changes in the height and apical width over this period (Figs 2 and 5). The coefficient of correlation between the frond size in relation to apical and middle widths was very low in all cases $(>0.59)$, which indicates that the growth is allometric. However, the correlation between frond size and the number of dichotomies was significant $(r=0.87)$, suggesting that the branching process is linked with thallus development

Spermatangia were observed in dense sori distributed throughout the thallus. This kind of arrangement corresponds to what Kajimura $(1988 ; 1991)$ named the "irregular type", and its occurrence in S. latifrons supports Yoshida (1998) who proposed that S. cottonii is a heterotypic synonym of $S$. latifrons because of the presence of both dioecious (Dawson, 1949) and monoecious plants (this study). However, since neither Yoshida nor us have examined the relevant type material, we do not propose this synonymy at this stage.

The growing season of the gametophyte phase of Scinaia latifrons as found during this study was shorter than those reported for other species of the genus and for species of closely related genera (Table 1). This shorter growing season is probably due to the environmental stresses that are found in the southwestern Gulf of California and because S. latifrons was found attached to mobile substrata (rhodoliths and shells), and therefore exposed to the characteristic disturbances of this environment (Marrack 1999), often caused by strong tidal currents, however it might be that in other less disturbed zones, gametophytes may persist for a longer period.

The gametophyte occurs when environmental conditions are similar to those typical of temperate environments. There are a few limiting factors known for these genera (Ramus 1969), such as nutrient availability and temperature. It is clear that the gametophytic phase occurred in San Lorenzo Channel during the season of greatest nutrient concentration and lower temperature (Álvarez-Borrego 1983). Temperatures in the region typically drop in November-December, which might induce the formation of the protonemal gametophyte, since it has been shown that these are probably seasonal in occurrence (Huisman 1987). It is possible that the sporophyte can occur throughout the year, since temperature tolerances are not known for the sporophyte of any species in the genera.

In the case of temperature and photoperiod, the analysis of correlation did not show positive results, and unfortunately no data on nutrients were available. However, we consider that the low number of observations $(n=5)$ might have some effect on the analyses.

\section{ACKNOWLEDGMENTS}

We acknowledge the critical reading of the manuscript by M.S. Foster (MLML-USA) and two anonymous reviewer who helped to improved the manuscript. This work has been develop with the support of CONACYT \# 056PÑ-1297 and CONABIO \# FB712/S074. We thank the help of G. Hinojosa-Arango, J.M. López-Vivas, E. Holguin-Acosta, M.C. Altamirano-Cerecedo in the field work and to A. Angles-Perez for the histological process. The second author thanks A. Ángeles-Pérez for her support for this study.

\section{REFERENCES}

Abbott I.A. and Hollenberg G.J. 1976. Marine algae of California. Stanford University Press, Stanford, California. 827 pp.

Aguilera V.C. and Ganesan E.K. 1981. Life history of the marine red alga Pseudogloiophloea halliae (Nemalionales, Chatangiaceae) in culture. Boletin Instituto Oceanografico Venezolano Universidad de. Oriente 20: 74-55.

Alvarez-Borrego S. 1983. Gulf of California. In: Ketchum C.B.H. (ed.), Estuaries and Enclosed Seas. Elsevier Scientific. Publ. 
Co., Amsterdam. 427-449 pp.

Dawson E.Y. 1949. Resultados preliminares de un reconocimiento de la Costa Pacífico de México. Rev. Soc. Mex. Hist. Nat. 9: 215-255. 1 chart.

Flores-Ramírez S. 1994. Ecología del rorcual común (Balenoptera edeni) en Bahía de la Paz, B.C.S., México. Unpublished Master in Science thesis. UABCS, Departamento de Biologia Marina 80 pp.

Foster M.S., Riosmena-Rodríguez R., Steller D.L. and J. Woelkerling Wm. 1997. Living rhodolith beds in the Gulf of California and their implication for paleoenviromental interpretation. In: Johnson M.E. and Ledesma-Vázquez J. (eds), Pliocene Carbonates and Related Facies Flanking the Gulf of California, Baja California, México. Special Paper 318. The Geological Society of America. U.S.A. pp.127-140.

Howe M.A. 1911. Phycological studies -V. Some marine algae of Lower California, Mexico. Bull. Torrey Bot. Club 38: 489-514

Huisman J.M. 1986. The red algal genus Scinaia (Galaxauraceae, Nemaliales) from Australia. Phycologia 25: 271-296.

Huisman J.M. 1987. The taxonomy and life history of Gloiophloea (Galaxauraceae, Rhodophyta). Phycologia 26: 167-174.

Kajimura M. 1988. Three New Deep-water Species of Scinaia (Galaxauraceae, Rhodophyta) from the Sea of Japan. Bot. Mar. 31: 175-185.

Kajimura M. 1991. Scinaia pseudo-moniliformis sp. nov.
(Galaxauraceae, Rhodophyta) from the Sea of Japan. Bot. Mar. 34: 513-520.

Marrack E. 1999. The relationship between water motion and living rhodolith beds in the southwestern Gulf of California, México. Pal. 14: 159-171.

Millar A.J.K. 1990. Marine algae from the Coffs Harbor region, northern New South Wales. Australian Syst. Bot. 3: 295-593 pp.

Ramus J. 1969. The developmental sequence of the Marine Red Alga Pseudogloiophloea in culture. Univ. Califor. Publ. Bot. 52: 1-42.

Robles-Gil M.S.G. 1998. El clima de la Ciudad de La Paz, Baja California Sur. MS Thesis. UNAM, México 233 pp.

Steller D.L., Riosmena-Rodríguez R., Foster M.S. and Roberts C.A. 2003. Rhodolith bed diversity in the Gulf of California: the importance of rhodolith structure and consequences of disturbance. Aquatic Conserv: Mar. Freshw. Ecosyst. 13: S5S20.

Yoshida J. 1998. Marine Algae from Japan. Uchikayada, Tokyo. 655 pp.

Zar J. H. 1996. Bioestatistical analysis. Third edition. Prentice Hall. New Jersey. 662 pp.

Received 24 September 2004

Accepted 31 January 2005 